\title{
HISTÓRIA DA PALESTINA DO PRIMEIRO SÉCULO: POSSÍVEIS CONTEXTUALIZAÇÕES E APRENDIZADOS
}

\section{ARTIGO ORIGINAL}

SILVA, José Roberto Limas da ${ }^{1}$

SILVA, José Roberto Limas da. História da Palestina do primeiro século: possíveis contextualizações e aprendizados. Revista Científica Multidisciplinar Núcleo do Conhecimento. Ano 05, Ed. 11, Vol. 21, pp. 66-76. Novembro de 2020. ISSN: 24480959, Link de acesso:https://www.nucleodoconhecimento.com.br/ciencia-dareligiao/contextualizacoes-e-aprendizados

\section{RESUMO}

O presente artigo tem o propósito de construir um resumido roteiro histórico, político e socioeconômico da Palestina do primeiro século. O caminho é demasiadamente complexo, mas lançaremos mão de uma análise historicista e cronológica a fim de compreendermos o pano de fundo onde são erguidas as bases do Novo Testamento cristão. Os fatos históricos, mencionados nesse texto, são um terreno comum, já mencionado por centenas de pesquisadores. Não obstante, a presente pesquisa demonstrará a necessidade de revisitar o tema, sobretudo, pela necessidade de contextualizar as mazelas sociais e políticas tão presentes e tão questionadas por Jesus nos evangelhos, especialmente as desigualdades econômicas e a marginalização dos pobres e grupos periféricos como estrangeiros, publicanos e prostitutas. O desenvolvimento do assunto desse artigo deixará visível, no palco da Palestina, o ambiente social, político, econômico e cultural em que foi desenvolvido o

${ }^{1}$ Doutorando em Teologia pela Faculdades EST em São Leopoldo/RS, bolsista da CAPES/PROSUC, mestre em Ciências da Religião, bacharel em Geografia/UFMG, graduando em Filosofia pela UNINTER. 
ministério de Jesus, bem como, o espaço vital onde ocorreram as narrativas dos evangelhos.

Palavras-chave: Palestina, primeiro século, Novo Testamento, Judeia, Império Romano.

\section{INTRODUÇÃO}

Inicialmente havemos de dizer que estudar a Palestina do primeiro século nos impõe várias exigências, a começar pela caracterização do nome Palestina. O nome dessa terra, chamada Palestina, como a conhecemos hoje, não é mencionado no Novo Testamento. A palavra Palestina é uma nominação dos gregos para a região conhecida como Filistia, uma estreita faixa litorânea do Mar Mediterrâneo, próxima à Judeia. Ocorre que com o tempo este nome Philistia, tornou-se Palestina, e a região toda (Canaã) passou a ser chamada de Palestina.

O nome bíblico para toda essa região é Canaã, Terra Santa, Terra Prometida etc. Essa região começa nas montanhas da Síria e vai até as estepes do Neguebe (deserto) no comprimento e do grande deserto da Arábia até o mediterrâneo na sua largura. Quando falamos de terra prometida, podemos nos reportar aos tempos de Salomão quando toda a Palestina (Canãa) foi ocupada pelos Hebreus (de Dã até Berseba).

Quanto à Palestina do primeiro século, essa tinha uma configuração geopolítica estabelecida pelos romanos, dividida basicamente nas seguintes regiões: Idumeia/Judeia, Galileia, Pereia e Decapólis. Quando falamos de Palestina no Novo Testamento, temos que ter em mente que esta região, em virtude de sua posição geográfica, "estava constantemente envolvida em políticas partidárias do Oriente Próximo antigo" (STAUMBAUGH; BALCH, 1996, p. 16), sendo assim o caminho de exércitos de conquistadores que saiam do Egito em direção à Mesopotâmia ou viceversa. 
Precisamos, também, entender todo o processo histórico para chegarmos à Palestina do primeiro século, dentro dessa configuração territorial romana. Faz-se necessário, primeiramente, revisitar a conquista do Oriente Próximo por Alexandre Magno, iniciando o processo de helenização desta região (nos anos de 331 a 333 a.C). Temos, nesse primeiro momento, um processo que vai configurar cultural e socialmente a Palestina do Novo Testamento. A cultura helênica vai influenciar o judaísmo Palestinense, que havia se estruturado no pós-cativeiro babilônico. Não obstante, teremos, a partir desse processo histórico, uma nova religiosidade judaica, que será constituída de grupos que apoiam a presença da cultura grega na religião judaica e os grupos fundamentalistas que resistirão a esse processo.

Imagem 1 - Palestina: 


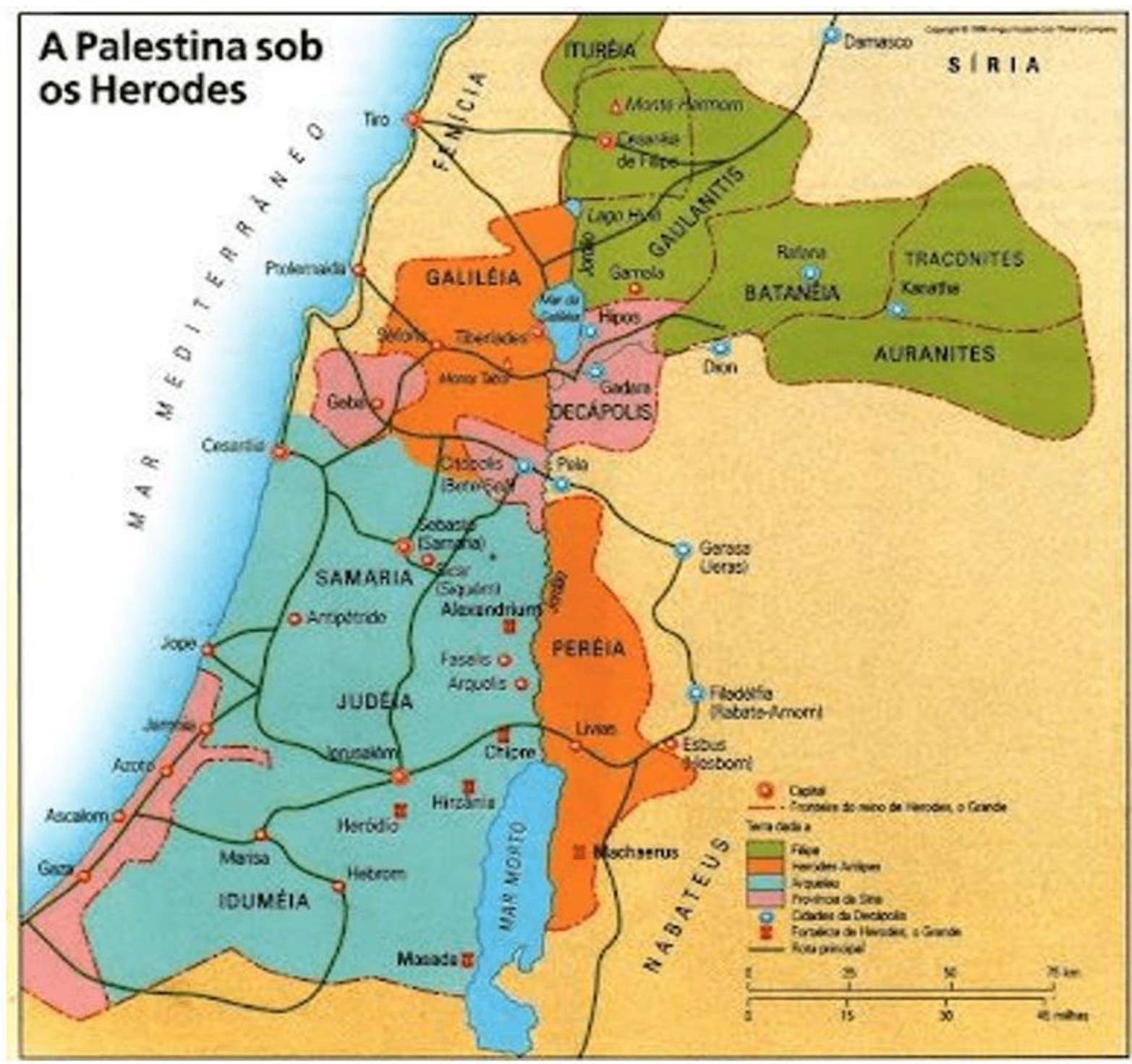

fonte: https://www.google.com/search?q=palestina

O período curto da vida de Alexandre desembocou na divisão do seu império em quatro grandes regiões (Egito, Mesopotâmia/Ásia Central, Anatólia e Macedônia), sendo que o território da Palestina ficou sob a influência da região Mesopotâmica/Ásia Central, com o governo dos Selêucidas ao norte (na Síria) e ao sul pelos Ptolomeus (no Egito). Esse território, assim, ficou num espaço que envolvia, então, certa disputa territorial entre os Ptolomeus e os Selêucidas. Sabemos que "a dinastia Selêucida na Síria foi de várias formas mais agressiva que a dos Ptolomeus. Em certas épocas sob Antioco III (223-187 a. C.), o seu reino abarcou a Armênia e os partos e até mesmo parte da Índia" (STAUMBAUGH; BALCH, 1996, p. 16). Já a 
dinastia dos Ptolomeus era mais tolerante com a vida cultural e religiosa da Palestina, em especial com os Judeus.

\section{AS RELAÇÕES ENTRE A DINASTIA SELÊUCIDA E A JUDEIA}

Os Seleucidas trouxeram grande desconforto para a Palestina, sobretudo a partir do governo de Antíoco Epifânio, "que invadiu Jerusalém depois de cento e quarenta e três anos que Seleuco e seus sucessores começaram a reinar na Síria" (JOSEFO, 2019, p. 561). Dito fato aconteceu quando Antíoco (que governava a Síria) voltava do Egito, duma batalha frustrante, e resolveu se valer do apoio de alguns partidários favoráveis a sua política helenizante da palestina, que abriram-lhe as portas da cidade de Jerusalém. Sendo assim, ele "mandou matar vários do partido contrário, apoderouse de grande quantidade de dinheiro e voltou à Antioquia" (JOSEFO, 2019, p. 561). Dessa forma, a hostilidade de Antíoco era constante sobre grupos de judeus mais ortodoxos, sendo que, após essa invasão mencionada acima, ele retornou dois anos depois,

despojando o Templo das muitas riquezas de que, sabia ele, estava cheio. Tomou os vasos consagrados a Deus, os candelabros de ouro, a mesa sobe a qual se punham os pães da proposição e os turíbulos. Levou até mesmo as tapeçarias de escarlate e de linho fino e pilhou tesouros que estavam escondidos havia muito tempo (JOSEFO, 2019, p. 561).

Nesse período, muitos judeus da Palestina incorporaram a cultura helênica às suas práticas religiosas e sociais, especialmente entre a "nobreza da alta classe de Jerusalém" (STAUMBAUGH; BALCH, 1996, p. 16), enquanto grupos tradicionais e fundamentalistas do Judaísmo resistiam com animosidade a este processo de aculturação do Judaísmo ao Helenismo. Nesse momento, a vida social e religiosa da Judeia está fragmentada e cercada de conflitos entre os grupos liberais (favoráveis ao estilo de vida grego) e os tradicionais (observadores estritos da Torah, como os Fariseus).

Esse quadro político instável era um terreno favorável para que Antíoco (dinastia Selêucida) estabelecesse um governo mais presente e atuante sobre a sociedade 
judaica, que por causa da sua religiosidade oferecia muita resistência ao seu projeto de "governar um reino culturalmente unificado" (STAUMBAUGH; BALCH, 1996, p. 16). Ademais, ele contava agora com o apoio dos judeus helênicos, que almejavam assumir o poder em Jerusalém. Este quadro ganhará contornos cada vez mais dramáticos, sendo que

entre 175 e 163 a. C., os helenizantes, cujos interesses eram impedidos pelas regulamentações detalhadas da Torah, romperam com as instituições tradicionalistas. Fundaram, encorajados por Antíoco, uma polis no estilo grego em Jerusalém, que completaram com um ginásio e um conselho dominado pelos nobres não-sacerdotais da família de Tobias. As tentativas alcançaram seu clímax em 167 a. C., quando Antìoco demoliu as muralhas da cidade de Jerusalém e construiu uma nova fortaleza (a Acra) para a guarnição síria. Estabeleceu-se no próprio Templo um culto dedicado ao deus grego Zeus, e Antíoco publicou decreto proibindo a prática da religião judaica na Judeia. Os tradicionalistas responderam com revolta armada. Sob a liderança de uma família de ricos sacerdotes rurais, que se costuma chamar de os Macabeus, a guerra contra os Selêucidas continuou por vinte anos. Em 164 a. C., Judas Macabeus abateu o culto de Zeus, que viera a se conhecer como a 'abominação da desolação', e restabeleceu o culto tradicional dos judeus, evento que ainda hoje se celebra no feriado da Hannukah. (STAUMBAUGH; BALCH, 1996, p. 16).

Com o prevalecimento dos Macabeus e a reestruturação da vida religiosa judaica, temos uma nova conjuntura política e social da Palestina, sobretudo por causa do recrudescimento dos ideais nacionalistas, bem como, de um estado teocrático, independente e expansionista. Ademais, os Macabeus expectavam uma reforma religiosa abrangente que visava a deselenização da Palestina e a conquista de prosélitos para a religião judaica.

\section{JUDEIA INDEPENDENTE SOB O GOVERNO DOS MACABEUS}

Esse momento da história ganha contornos marcantes, pois marca a aproximação dos romanos da Palestina por iniciativa dos Macabeus. Com a vitória dos Hasmoneus, Judas Macabeu é nomeado sumo sacerdote, que "constatando que o poder dos romanos era tão grande que eles haviam submetido os Gálatas, os espanhóis e os 
cartagineses, subjugado a Grécia e vencido os reis Perseu, Filipe e Antioco, o Grande, resolveu fazer amizade com eles \{...\}" (JOSEFO, 2019, p. 581).

Os romanos, que tinham grande interesse na região da Palestina, até porque significava o livre acesso ao Egito, e com esse horizonte em mente, estabeleceram o primeiro tratado com a dinastia dos Macabeus. O tratado era amplamente favorável aos Macabeus e oferecia a segurança que precisavam no ambiente hostil da Palestina, em face de possíveis retaliações da dinastia dos selêucidas. O teor do tratado era basicamente esse:

Nenhum dos que estão sujeitos aos romanos fará guerra aos judeus, tampouco auxiliará os seus inimigos com trigo, navios ou dinheiro. Os romanos ajudarão os judeus com todas as suas posses contra os que os atacarem, e os judeus auxiliarão os romanos do mesmo modo, se estes forem atacados. Se os judeus quiserem acrescentar ou diminuir alguma coisa a esta aliança que contraem com os romanos, não o poderão fazer sem o consentimento de todo o povo romano, que deverá ratificá-lo (JOSEFO, 2019, p. 581).

Nessa perspectiva de apoio e proteção romana, após a morte de Judas Macabeu, é nomeado como sumo sacerdote, Jônatas, que acumulou a posição de governador também. $\mathrm{E}$, assim, a partir de $152 \mathrm{a}$. C começa este processo de um governo religiosopolítico na Judeia. Já em 143 a. C., Jônatas é sucedido pelo seu irmão Simão, obtendo isenção de impostos em 142 a. C., data que marca o início da independência da Judeia.

Com o estabelecimento da família dos Macabeus, é definida uma dinastia vitalícia na Judeia, chamada dos Hasmoneus que vai permanecer até o ano 63 a. C. Esse é um período em que a Palestina passa a ser totalmente dominada pelos Judeus, agora, patrocinados pelo apoio político de Roma. Com esse apoio, os Hasmoneus vão ampliar continuamente seu território, anexando a Idumeia (região dos árabes), cidades do litoral mediterrâneo e a região de Decápolis (cidades de cultura helenizada). A geopolítica Hasmoneia era baseada especialmente na imposição do Judaísmo e na remoção da cultura helênica, "abolindo as instituições típicas como o ginásio e os templos pagãos" (STAUMBAUGH; BALCH, 1996, p. 16). Uma importante 
observação a ser feita neste ponto é que a dinastia dos Herodes, que vai governar a Palestina (ou parte dela) por longo período, vai proceder desta anexação da Idumeia aos interesses políticos judaicos.

Os traços de corrupção e degeneração foram se evidenciando na dinastia Hasmoneia, como acontecesse costumeiramente em toda dinastia, com brigas familiares, conflitos entre as seitas do judaísmo, perseguição política, desencadeando uma guerra civil na Judeia. Nesse estado de coisas, os Romanos que acompanham as mazelas políticas da família dos Hasmoneus, resolveram intervir. Desta forma, no ano 63 a. C, o general Pompeu entrou em "Jerusalém, sitiou e conquistou a área do templo, provocou um banho de sangue, entrou e profanou o Santo dos Santos e assumiu a Judeia como Estado-vassalo de Roma sob a fraca autoridade do sumo sacerdote Hircano II, do qual tirou o título de rei" (DONNER, 1997, p. 512).

Nesse primeiro momento do domínio Romano, a Palestina foi anexada à Síria (sede da antiga dinastia Selêucida), devolvendo autonomia política às regiões como a de Decápolis e removendo o acesso da Judeia ao mediterrâneo. Em suma, a configuração política e geográfica da Palestina ficou mais reduzida, voltando à configuração anterior ao governo dos Hasmoneus.

\section{A DINASTIA DOS HERODES NA PALESTINA}

A anexação da Idumeia e a ligação da família dos Herodes à família dos Hasmoneus viabilizaram a introdução dos Herodes no governo da Palestina, em face do momento de fraqueza político-religiosa dos Hasmoneus, depostos na invasão romana. Outro fato importante para a introdução da dinastia Idumeia na Palestina, foram as boas relações que os Herodes possuíam com os Romanos, devido aos serviços militares prestados pelos Herodes quando Jerusalém foi invadida pelos Partos, sendo reassumida posteriormente por Herodes, apoiado pelo governador da Síria.

Dessa forma, a família Herodes conseguiu os auspícios dos Romanos em 43 a. C, sendo Herodes declarado como rei de uma Judeia que "abarcava a Galileia, a Pereia e Samaria" (STAUMBAUGH; BALCH, 1996, p. 18). Num futuro próximo, Herodes vai 
receber o controle de numerosas cidades gregas da costa do mediterrâneo e vai distribuir a população da Judeia, reduzindo "a superpopulação no território judaico original" (STAUMBAUGH; BALCH, 1996, p. 19).

Podemos dizer que este Herodes se considerava "o senhor da Palestina na época do nascimento de Jesus como um daqueles príncipes vassalos a quem os grandes usam e toleram \{...\}" (ROPS, 2008. p. 76). Era um mal necessário para os romanos, que precisavam de uma liderança leal na Palestina. O papel de vassalo leal foi sempre cumprido com maestria por Herodes, pois estava sempre a cargo dos melhores serviços romanos. A Palestina do nascimento de Jesus é assim, então, governada por um homem poderoso que dirigia com mão de ferro a mesma, com poder de nomear, inclusive o sumo sacerdote do templo. Não obstante, "uma grande parte da opinião pública (entre os judeus) estava contra ele, por ser Idumeu, praticamente incircunciso, um filho de Esaú \{...\}” (ROPS, 2008. p. 77).

Resumindo este período de Herodes (37 a. C - 4 a. C), podemos dizer que a vida política de Israel se apresentou sempre conturbada e à beira de levantes e conspiratas, sempre abafadas de forma violenta pelo mesmo Herodes. A rotina do governo de Herodes pode ser resumida assim:

Num dia o povo ficava sabendo que centenas de fariseus tinham sido enforcados por criticar em voz demasiado alta o governador, em outro que trezentos oficiais, suspeitos de conspiração em Samaria, tinha sido linchados por uma multidão atiçada pela polícia; ou talvez que os jovens que haviam tentado remover a águia dourada colocada pelo tirano no portão do templo foram apedrejados ou queimados vivos. Num clima de tanta violência o Massacre dos Inocentes no Evangelho se enquadra com perfeição e naturalidade" (ROPS, 2008. p. 79).

Após a morte de Herodes, o governo da Palestina foi fracionado entre seus filhos, destinando as regiões de Idumeia, Judeia e Samaria para Arquelau Herodes; Antipas Herodes ficou com a Galileia e Filipe ficou com a região de Basã. Entretanto, Arquelau não conseguiu suportar as pressões e os conflitos na região da Judeia, sendo substituído por Procuradores Romanos. Dessa maneira, as regiões onde Jesus desenvolveu seu ministério efetivamente (Galileia e Judeia) eram governadas por dois 
atores principais: Na Judéia e Samaria, um oficial romano; na Galileia, Herodes Antipas.

Feitas estas breves considerações sobre o cenário político da Palestina, vamos pensar no cenário social da Palestina no Novo Testamento.

\section{A SOCIEDADE DA PALESTINA DO PRIMEIRO SÉCULO}

A maioria da população era campesina, vivendo em aldeias e não em grandes cidades. Essa realidade não era muito diferente do restante do Império Romano, que tinha na população rural a esmagadora maioria. $E$ isso é explicado pelo fato de a economia do "Império Romano estar baseada nas atividades agrárias" (ALFOLDY, 1989 , p. 114) e diferentemente do que muitos pensam, a economia do Império não era movida primeiramente pelos tributos ou pelas operações comerciais, mas pelas atividades agrícolas. Situação semelhante era vivida no ambiente da Palestina, estando a maioria da população envolvida com atividades do campo, haja vista as muitas parábolas contadas por Jesus, enfatizando o mundo rural (pastores, agricultores, pescadores etc).

A demografia urbana é bastante surpreendente, nesse sentido, uma vez que as grandes cidades eram exceção, prevalecendo as cidades pequenas, sendo que "a maior parte das mais de 1000 cidades do Imperium Romanum tinha provavelmente uma população de 10.000 a 15.000 habitantes" (ALFOLDY, 1989, p. 114). "Uma cidade com mais de 20.000 habitantes (como Pompeia) já era considerada uma cidade média, enquanto eram muito poucas as cidades com uma população de 50.000 a 100.000 habitantes, como Pérgamo \{...\}" (ALFOLDY, 1989, p. 114). Assim, as únicas grandes cidades, "além de Roma, cujo número de habitantes é calculado em talvez 1.000.000, eram Alexandria no Egipto e Antioquia na Síria, com algumas centenas de milhar" (ALFOLDY, 1989, p. 114).

Imagem 2- Mapa do Império Romano - início do segundo século: 


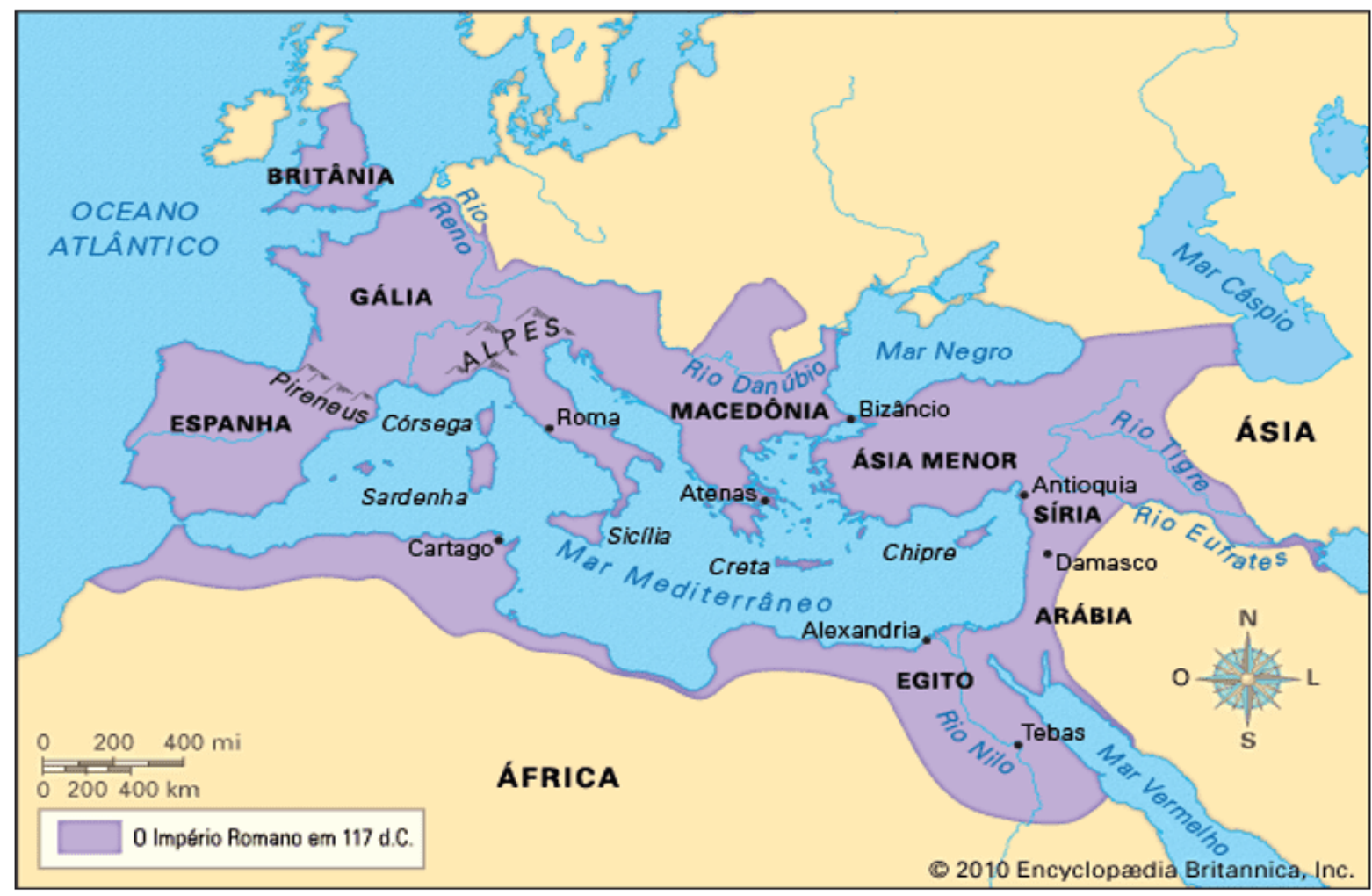

Fonte: Disponível em: https://www.google.com/search?q=

Com relação à estratificação social e às condições econômicas da população na Palestina, "a grande maioria dos judeus, nos tempos em que Jesus viveu na Galileia, Transjordânia e Judéia, vivia em pequenas aldeias, e não em grandes cidades como Tiberíades e Jerusalém" (STAUMBAUGH; BALCH, 1996, p. 74), e isso explica o fato de Jesus privilegiar sua missão no ambiente de pequenas comunidades e no campo, como se vê nesta passagem do Novo Testamento: "Ao cair da tarde, vieram os discípulos a Jesus e lhe disseram: O lugar é deserto, e vai adiantada a hora; despede, pois, as multidões para que, indo pelas aldeias, comprem para si o que comer" (ALMEIDA, 2008, p. 1268)

Outra questão que explica muito as condições sociais e econômicas da população da Palestina, eram as moradias precárias, havendo famílias mais pobres que moravam num cômodo só, fator agravado pelo fato de que "era raro que as pessoas ficassem sem se casar" (STAUMBAUGH; BALCH, 1996, p. 75), além de ser comum a geração de muitos filhos, impactando ainda mais a economia doméstica. Nesse contexto social 
de uma população basicamente rural e uma economia essencialmente agrícola, o atestado de prosperidade era a posse da terra. A realidade na Palestina, como nas demais regiões do Império Romano, era de polarização dos grupos sociais, os ricos possuíam a posse da terra e os pobres trabalhavam nela, de forma precária e sem a retribuição econômica suficiente para a sua manutenção. Somos informados de que "muitos romanos ricos, entres os quais a maioria dos senadores, como por exemplo, Plínio o Jovem ou Herodes Ático, muitos cavaleiros e a maioria dos decuriões da cidade deviam a sua fortuna às propriedades rurais que possuíam \{...." (ALFOLDY, 1989, p. 114), enquanto os pobres realizavam o trabalho braçal no campo.

Esse quadro de desigualdade social encontrava-se espalhado por todo o território do império e temos conhecimento sobre a concentração de terras (latifúndios) nas mãos de uma pequena parcela da população, sendo que "nas províncias mediterrânicas, como em África, onde em meados do século I d. C., as propriedades de seis grandes proprietários, cobriam metade do país \{...\}" (ALFOLDY, 1989, p. 123). Essa infeliz e desigual distribuição de riquezas acentuava os problemas sociais e a miséria da população pobre, pois os modos de vida de ricos e pobres eram radicalmente diferentes, uma vez que as famílias ricas moravam em palácios luxuosos, enquanto os pobres moravam amontoados em casebres, o que patrocinava relações sociais opressivas onde os pobres se sujeitavam a humilhações constantes (ALFOLDY, 1989, p. 123).

A compreensão de sua posição no extrato social, por parte do morador da Palestina, diferia razoavelmente da leitura que o resto da população do império fazia. Rops (2008) analisa essa diferença de percepção do judeu palestinense em relação às demais nações:

O que isolava, porém, completamente Israel das demais nações do mundo antigo era a sua atitude em relação a esta desigualdade social e aos privilégios da riqueza. O princípio religioso era absoluto: com exceção da classe sacerdotal, que era tida como possuindo uma graça especial, todos os leigos judeus mantinham estritamente uma posição de igualdade entre eles (...). Quer dizer, somos iguais, sou tão bom quanto eles. Um humilior romano encontrando um abastado patrício em sua toga listada de púrpura a caminho do senado, com todos os seus 
clientes à sua volta, não sentia um igual; mas o mais desgraçado dos fiéis, de pé no átrio do Templo, com os braços levantados para o céu em oração, sabia que aos olhos de Javé ele era tão bom quanto Herodes" (ROPS, 2008. p. 161).

Esse sentimento de ser digno de uma vida melhor, de não se sentir inferiorizado em relação ao indivíduo que está numa posição econômica ou social acima da sua, produziu no judeu a crença de que a pobreza e a miséria são circunstanciais e não uma condição irrevogável e imutável. Isso acentuava a luta entre classes (no dizer moderno de Marx) e possibilitava a mobilidade social, uma vez que a pobreza era uma condição eventualmente provisória e que precisava ser acompanhada de certa dose de inconformismo.

Essa perspectiva explica muito o quadro de conflitos sociais presentes na Palestina Judaica, evidenciado nos textos dos evangelhos. Percebe-se, claramente, que o equilíbrio da sociedade parecia incerto e sua solidez, precária, prevalecendo a inimizade entre as classes por quaisquer motivos, sejam eles políticos, sociais ou religiosos. Um clima constante de animosidade ronda a Palestina do Novo Testamento, sendo que "o povo comum se sentia miserável, se apegava a qualquer esperança e a quaisquer homens que, guardando a fé, Ihes oferecessem um futuro melhor" (ROPS, 2008. p. 181). Este é o terreno fértil onde a mensagem do Novo Testamento vai ser proclamada pela igreja judaica da Palestina.

\section{CONSIDERAÇÕES FINAIS}

A compreensão do processo histórico que desemboca na Palestina do primeiro século é essencial para percebermos os matizes sociais e religiosos do Novo Testamento. $O$ ministério de Jesus não acontece num vácuo cultural e social, pelo contrário, seu discurso vai ao encontro de um sistema social e político opressivo e marginalizador do morador da Palestina e, evidentemente, estendido a todo ser humano. Essa compreensão será tanto mais produtiva se feita de uma forma sistêmica e transdisciplinar, considerando todos os elementos sociais, políticos, filosóficos e religiosos que estão em torno da narrativa bíblica. 
Nesse sentido, o estudo da Palestina do primeiro século nos ajuda a refletir sobre o modus vivendi de nossa geração que, de certa maneira, repete as injustiças sociais dessa época e que foram combatidas por Jesus com suas palavras, seu suor, suas lágrimas e seu sangue derramado na cruz.

\section{REFERÊNCIAS}

ALFOLDY, Geza. A história social de Roma. Lisboa: Presença, 1989.

ALMEIDA, João Ferreira. Bíblia Sagrada. $2^{\underline{a}}$ Ed. São Paulo: Sociedade Bíblica do Brasil, 2008.

DONNER, Herbert. História de Israel e povos vizinhos. São Leopoldo: Sinodal, 1997.

JAEGER, Werner. Cristianismo Primitivo e Paidéia Grega. Lisboa: Edições 70, 1991.

JOSEFO, Flávio. História dos Hebreus. Rio de Janeiro: Cpad, 2019.

ROPS, Henri Daniel. A vida diária dos tempos de Jesus. São Paulo: Vida Nova, 2008.

STAUMBAUGH, John E.; BALCH David L. O Novo testamento em seu ambiente social. São Paulo: Paulus, 1996. 